\title{
BERRO! Uma educação transviada em química
}

DOI 10.26512/lc.v24i0.19702

\author{
Allan Moreira Xavier \\ Centro de Ciências Naturais e Humanas/Universidade Federal do ABC \\ allan.xavier@ufabc.edu.br
}

\section{Resumo}

Pode a química, e seu ensino, permitir-se enviadecer? A partir de uma prática de pesquisa-escrita, este ensaio propõe-se a discutir aspectos epistemológicos característicos da química, a possibilidade de uma produção rizomática deste saber e as consequências das desestabilizações produzidas pelo pensamento queer no discurso da química. Sugere uma educação pelo cu, a partir da qual serão liberadas as potências micropolíticas ativas, envolvidas em produções de monstros que nos direcionarão a explorar as potências de viver em devir.

Palavras-chave: Ensino de Química. Pensamento Queer. Potências Microcopolíticas. 


\section{Abstract}

Can chemistry, and its teaching, allow itself to be queer? From a research-writing practice, this essay proposes to discuss epistemological aspects characteristic of chemistry, the possibility of a rhizomatic production of this knowledge and the consequences of the destabilization produced by queer thought in the discourse of chemistry. It suggests an education through the anus, from which will be released the active micropolitical powers involved in the production of monsters that will lead us to explore the powers of living as becoming.

Keywords: Chemistry Education. Produced by Queer. Micropolitical Powers.

\section{Résumé}

La chimie et son enseignement peuvent-ils se laisser pedê? A partir d'une pratique de recherche-écriture, cet essai propose de discuter des aspects épistémologiques caractéristiques de la chimie, la possibilité d'une production rhizomatique de cette connaissance et les conséquences de la déstabilisation produite par la pensée queer dans le discours de la chimie. Il suggère une éducation à travers le cu, d'où sortiront les pouvoirs micropolitiques actifs impliqués dans la production de monstres qui nous conduiront à explorer les pouvoirs de vie à venir.

Mots-clés: Ensenignement de Chemie. Penseé Querr. Pouvoirs Micropolitiques. 


\section{Resumen}

¿Puede la química y su enseñanza permitirse ser raro? A partir de una práctica de escritura de investigación, este ensayo propone discutir aspectos epistemológicos característicos de la química, la posibilidad de una producción rizomática de este conocimiento y las consecuencias de la desestabilización producida por el pensamiento queer en el discurso de la química. Sugiere una educación a través del ano, a partir de la cual se liberarán los poderes micropolíticos activos que participan en la producción de monstruos que nos llevarán a explorar los poderes de la vida como devenir.

Palabras clave: Enseñanza de Química. Pensamiento Queer. Poderes Micropolíticos.

Pervertido, mal-amado, menino malvado, muito cuidado! Má influência, péssima aparência, menino indecente, viado!

(Caio Prado)

\section{Introdução}

Tornei-me químico por insistência. Aquelas palavras que hoje fazem parte do discurso da química que carrego comigo, estavam razoavelmente distantes do meu cotidiano enquanto criança e adolescente, ainda que as ciências sempre tivessem exercido um encantamento mágico, irracional e lúdico durante nossos encontros na escola e na mídia. Muito antes de perceber que este saber estava codificado e distanciado, e que obtê-lo aconteceria apenas quando da superação de uma série de ritos e escolhas, eu já estava preocupado como "Bicha!" pelo qual era constantemente nominado. Também aprendi o significado deste xingamento no ambiente escolar, mesmo que numa tentativa de proteção, a professora repetidamente afirmava que bicha era um verme que vivia na barriga de gente suja. Cresci com esta relação: meu desejo, minha existência, era o análogo a uma doença. Dos que não se cuidavam, dos que se sujam, dos que abusam do instinto em detrimento do saber científico. Foi um professor, que atraia para si atenção e chacota dos alunos por movimentar-se e falar em tom afeminado, quem me deu coragem para escolher a carreira da química no vestibular, mas não foi por ele que eu percebi que os fenômenos químicos faziam meus olhos brilharem: era o repetido feitiço do "sangue do diabo" - uma mistura de 
solução de amônia diluída com fenolftaleína - que marcavam as roupas de vermelho, mas que desapareciam após algum tempo. Nenhum familiar ou amigo próximo poderia supor a minha escolha profissional, e foi o primeiro armário que tive de romper. Imensas brigas e testes constantes questionavam minha aprendizagem na graduação, como se, por estudar química, eu tivesse me tornado o mago que resolveria todos os problemas do mundo. Um deles eu ainda não conseguia resolver com feitiços. Precisei escapar do radar violento da figura heteronormativa familiar para que a bicha pudesse realizar outros encantamentos. Beijos a luz do dia, andar de mãos dadas na rua, flertar e trocar telefone. Tudo isso foi possível quando tomei outra terra como minha, como se a vida universitária permitisse algum afrouxamento das ofensas. Tolo era, menino eu. As chacotas continuaram, transferidas dos colegas para os endeusados doutores que me ensinavam a ser profissional, neutralizando minha existência em favor de uma leitura limpa do mundo material. Precisei insistir aos xingamentos, às violências, às discussões, aos apagamentos. $\mathrm{E}$ a bicha insistiu à química. O cheiro das baladas, o da refração do raio laser numa fumaça de gelo seco. A mão deslizando no lubrificante, a busca pelo resultado "não-reagente" dos exames de sangue que passaram a ser periódicos. A marca da tinta do holerite que borrava a mão, a aderência da comida servida na bandeja, a água de chuca. A química não estava em tudo, como vulgarmente diziam, porque para mim a química era viada. Eu não acessava lugares, comportamentos, compreensões. Foram estas experiências, entre elas a química, quem permitiram que hoje a bicha escreva este ensaio. Uma bicha insistente que se tornou um professor-viado.

Para tal análise, tratarei de discutir algumas das perspectivas que colocam em questionamento a epistemologia em que foi elaborada a química, e como podemos reelaborá-la em função dos estudos de gênero e dos estudos queer. Optei pelo formato de ensaio, apoiado na compreensão de Gough (2007), tendo em vista que para que a pesquisa em educação científica deva ser responsabilizada e relevante ao nosso mundo contemporâneo, deve-se desenvolver caminhos metodológicos para conhecer a desordem e elucidar os processos, as políticas, os poderes e as suas consequências para a educação em ciência. Pretendo, com este texto, uma "escrita como pesquisa" (Richardson, 2001), colaborar com questionamentos que permitam pensar o lugar da inclusão, mas especialmente a desestabilização que a consideração das estranhezas permitiria ao desenvolvimento do ensino da química. 
XAVIER, ALLAN. BERRO! Uma educação transviada em química. 


\section{Sobre as marcas de uma epistemologia da química e do ensino de química}

Ilude-se quem pensa que a compreensão dos conhecimentos químicos é garantida por uma boa formação escolar, por uma disposição para o conhecimento. Pela organização efetiva de uma aula, seja lá de que aula for. O conhecimento químico faz parte de um discurso, cujo objetivo é selecionar aqueles autorizados a falar sobre, a construí-lo. Assumo aqui a compreensão de discurso elaborada por Michel Foucault (2013), especialmente em sua A Arqueologia do Saber.

Foucault (2013) ultrapassa o entendimento de discurso como mera referência a coisas, isto é, discurso não é um fenômeno de mera 'expressão' de algo. Para o autor, discurso apresenta regularidades intrínsecas a si mesmo, através das quais é possível definir uma rede conceitual que é própria.

Certamente os discursos são feitos de signos; mas o que fazem é mais que utilizar esses signos para designar coisas. É esse mais que os torna irredutíveis à língua e ao ato da fala. É esse mais que é preciso fazer aparecer e que é preciso descrever (Foucault, 2013, p. 60).

O conceito de enunciados aparece intrinsicamente relacionado com o conceito de discurso. Aqueles são entendidos como funções de existência, a qual se exerce sobre unidades como a frase, a proposição, o ato de linguagem. É acontecimento, na medida em que nem a língua nem os sentidos podem esgotar inteiramente (Fischer, 2012, p. 77). Esta função é caracterizada por quatro elementos: um referente, um sujeito, um campo associado, uma materialidade específica.

Percebo que não podia definir o enunciado como uma unidade de tipo linguístico (superior ao fenômeno da palavra, inferior ao texto); mas que eu estava lidando com uma função enunciativa que envolvia variadas unidades (que podem às vezes ser sentenças, às vezes proposições, mas são algumas vezes compostas de fragmentos de sentenças, séries ou tabelas de signos, um conjunto de posposições ou formatações equivalentes); e, ao invés de dar um "significado" a essas unidades, essa função as relaciona com um campo de objetos; ao invés de lhes fornecer um sujeito, as abre para um certo número de posições positivas subjetivas positivas; ao invés de lhes fixar limites, as coloca em um domínio de coordenação e coexistência; ao invés de lhes determinar a identidade, as coloca em um espaço no qual elas são usadas e repetidas (Foucault, 2013, p. 129).

Descrever enunciados é dar conta dessas especificidades e apreendê-lo como acontecimentos, procedendo à individualização de formações discursivas. Por formação discursiva compreende-se um feixe complexo de relações que funcionam como regra: prescreve o que deve ser relacionado a uma prática discursiva para que se refira a um objeto ou empregue tal enunciado. 
O discurso da química reúne os mais diversos enunciados, leis, expressões, símbolos que implicam um jeito de pensar o mundo específico. Eles fazem sentido apenas na sua relação entre si, garantindo acesso ao mundo apenas aos iniciados neste discurso.

O discurso, assim concebido, não é a manifestação, majestosamente desenvolvida, de um sujeito que pensa, que conhece, e que o diz: é, ao contrário, um conjunto em que podem ser determinadas a dispersão do sujeito e sua descontinuidade em relação a si mesmo. É um espaço de exterioridade em que se desenvolve uma rede de lugares distintos (Foucault, 2013, p. 66).

Quanto a formação de conceitos químicos, algumas das unidades discursivas que estruturam esta formação discursiva científica particular, Bachelard (1996) nos ajuda a identificar, ao analisar a história da química, alguns elementos que apontem verdades imediatas e absolutas que impedem o desenvolvimento do conceito científico e de sua compreensão, os quais chama de obstáculos epistemológicos. São entendidos como entraves, inerentes ao próprio conhecimento científico, que bloqueiam seu desenvolvimento e construção. O filósofo argumenta que estamos sempre conhecendo contra um conhecimento anterior, num constante processo de desilusão de racionalidade científica, a partir de rupturas com conhecimentos anteriores, um processo de ir e vir da racionalidade.

Bachelard (2009a) argumenta que a química moderna se destaca por possuir uma epistemologia completamente nova. Nela, o conhecimento é um desejo alternativo de identidade e de diversidade. Na química, as propriedades de uma substância em particular acionam outros corpos químicos. Então, "se apreende a relação que vai de uma substância particular para seus atributos pelo único fato de se conhecer o lugar da substância no plano geral de todas as outras substâncias". Por este método, o estudo de um objeto não deve apagar as suas singularidades, mas a generalidade pode ser decifrada encontrando singularidades mais ou menos atenuadas em outro objeto. O conhecimento de uma substância particular pode ser aprimorado, precisado, multiplicado, pelo conhecimento de uma substância diferente - ou extensivamente, pelo conhecimento do conjunto de substâncias.

A verdadeira tarefa de uma filosofia química, afirma Bachelard (2009a), é a de destacar o caráter correlativo das noções de química buscando suas rupturas entre empirismo ingênuo e racionalismo puro (avançando assim, no que o filósofo designa de polaridade epistemológica). O químico procede, em um primeiro instante, guiado pela metafísica do realismo, mas, ao procurar qualidades, ele encontra leis. Químicos generalizam as qualidades, tomadas como algo singular. Essa relação, entre o diverso e o específico, que Bachelard (2009a) chama de pluralismo coerente da química moderna, é característica desta ciência e dos discursos que produz.

Os escritos de Bachelard têm sido muito utilizados para rediscutir o ensino de química. Ainda na década de 1990, Mortimer (1992) discute a possibilidade de utilizar a ideia 
de Bachelard de perfil conceitual (2009b) para traçar, para cada noção científica, uma linha evolutiva de acordo com sua posição na história da ciência e na estrutura cognitiva do indivíduo. Desta maneira, um conceito científico pode ser descrito em função dos componentes em termos de perfil: animismo, realismo, empirismo, racionalismo clássico e racionalismo moderno, sendo que apenas neste último seria encontrada a condição de desenvolvimento de pluralismo coerente. $\mathrm{O}$ autor aponta que para o ensino, os reflexos imediatos constituem tratar das diferentes zonas do perfil para cada conceito, indicando as zonas de ruptura e evitando a compreensão de desenvolvimento linear e cumulativo da ciência, marcas do positivismo. Assim, uma educação química deve considerar necessariamente a história dos conceitos químicos. Lôbo (2007) defende que, a partir da noção de vigilância epistemológica proposta por Bachelard, na qual deve-se mobilizar a razão e liberar os preconceitos dos conhecimentos mal estabelecidos, seja também aplicado na ação docente, evitando que professores sejam capturados pelos hábitos intelectuais, impedindo o avanço dos obstáculos pedagógicos relacionados à prática educativa como a reprodução de visões obstaculizadas da ciência e do ensino.

Cachapuz e colaboradores (2005) apresentam um conjunto de visões deformadas de ciência e tecnologia que devem ser superadas na formação de professores de ciências: a visão descontextualizada compreende a ação científica como socialmente neutra e considera a tecnologia uma mera aplicação dos conhecimentos científicos, tal visão isola o trabalho do cientista, atribuindo ao conhecimento produzido o papel de descobertas; a visão empírico-indutivista defende o papel de uma observação e experimentação neutras, esquecendo o papel das hipóteses na definição dos experimentos e do corpo teórico que acompanha a compreensão dos fenômenos; a visão algorítmica da ciência estabelece o trabalho científico como uma série de etapas rígidas e definidas que contribuem para a exatidão e objetividade dos resultados obtidos; no caso da visão ahistórica, a apresentação de conhecimentos prontos enfraquece o trabalho científico porque elimina a construção histórica da ciência e possibilita a inserção de obstáculos epistemológicos que serão necessários superar; já a visão exclusivamente analítica surge de uma vontade de simplificação e controle de condições que ignora muitas características de problemas estudados e deixa de lado a maior necessidade de síntese e complexidade dos sistemas em estudo; a visão acumulativa representa a compreensão de crescimento científico linear, ignorando as crises e rupturas epistemológicas necessárias que complexificam os processos e as teorias científicas. Para superar tais visões deturpadas, Cachapuz e colaboradores sugerem atividades que questionem o trabalho científico e estimulem a reflexão epistemológica, inclusive alterando o caráter expositivo dos currículos e aulas para uma prática pautada na investigação.

Lôbo (2012) observou que para alunos graduandos em química, a concepção de trabalho experimental varia entre comprovação e aplicação de teorias, observação de propriedades e fenômenos, desenvolvimento de habilidades, estudos de situações 
reais e concretas, recursos para motivação e investimento no trabalho de pesquisa e em sua relação entre teoria e prática. Já no caso de docentes, esta variação aumenta incluindo a ampliação da construção do conhecimento pela prática, com acesso a equipamentos e técnicas, a leitura crítica de roteiros experimentais e o desenvolvimento do raciocínio científico. A pesquisa realizada pela autora apontou para necessidade de aprofundamento do debate epistemológico, uma vez que estão presentes nos currículos obstáculos associados a concepções inadequadas da química, com ênfase no empirismo.

Os trabalhos de Ramos e colaboradores (2011) e Rezende e colaboradores (2010) seguem na mesma direção, apontando neste as concepções inadequadas de ciências em textos produzidos por licenciandos em química e, naquele, por professorespesquisadores da área de ciências biológicas. Ambos enfatizam a necessidade de romper com o modelo científico, que dicotomiza a relação teoria-prática na formação científica.

Foucault (1979) em uma conversa com Gilles Deleuze, indica que a teoria é um sistema regional de uma luta, luta não para tomada de consciência e para o esclarecimento das massas, mas para a destruição progressiva e tomada do poder ao lado de todos os que lutam por ela, contra o poder para fazê-lo aparecer e feri-lo onde ele é mais invisível e insidioso. Desta maneira, a teoria não expressa ou traduz ou aplica uma prática, ela é propriamente uma prática: local e regional, não totalizadora. Esta possibilidade avança na resolução do binômio limitador da teoria-prática.

Na maioria dos currículos, a química é tratada como teórica e prática e tal separação impede que se estabeleça este regime de luta para a dissolução dos regimes de poder em que está envolvida. Entretanto, na superação deste binômio, está o mapeamento da formação discursiva da química e, portanto, a possibilidade de elaborar resistências que ultrapassem o próprio discurso.

Em um exemplo do mapeamento de práticas discursivas que podem ser realizadas ao redor do discurso da química, Demeo (2005) estudou como são utilizados critérios de controle do corpo de estudantes em aulas de laboratório numa disciplina de química introdutória ao valorizar a manipulação de instrumentos, produzindo notas que refletem a precisão da manipulação e a atenção aos aspectos de segurança. Ficam marcadas as estratégias de controle desejáveis para o trabalho com química e/ou em ambiente químico (como o laboratório). $\mathrm{O}$ autor ainda aponta que na progressão na carreira como químico, existe um decréscimo de importância nas habilidades de manipulação - consequência de uma alteração da posição de sujeito e sua relação na malha de saber-poder: um químico experiente é valorizado pela sua capacidade de produzir conhecimento sobre a capacidade de manipulação dos outros. Este é um bom exemplo da dispersão capilar, móvel e fluída das relações de poder, distribuindo-se por todo o diagrama de relações (Silva, 2004).

Cardoso e Paraíso (2015) avaliaram, nas aulas de ciências de uma escola pública de Belo 
Horizonte, as demandas pelo estabelecimento de um dispositivo de experimentação. Compreendendo experimentação como um dispositivo que avança os muros das escolas e é recorrentemente chamado pela mídia, pela política e pela academia, as autoras descrevem-na como dispositivo que responde à urgência de se definir o que conta como ciência moderna ou não, o que é possível ou não de ser comprovado experimentalmente. Desta maneira, precisamos pensar na experimentação como um dispositivo que aciona tecnologias de subjetivação, demandando este sujeito da experimentação, o homo experimentalis, em diferentes instâncias, espaços, instituições, atendendo a seus deveres - racionalidade, objetividades, empiria, ordenação, lógica - usufruindo dos seus direitos de autoridade.

Deleuze e Guattari (1997) opõem dois tipos de ciência, ou procedimentos científicos: um reprodutivo e outro itinerante. Enquanto o ideal estriado da reprodução, dedução ou indução faz parte da ciência régia e trata as diferenças de tempo e lugar como tantas outras variáveis em que a lei extrai uma forma constante, reproduzir implica permanência de um ponto de vista fixo e exterior, reterritorialização em um domínio. Quando estamos à procura das singularidades, e não buscando uma forma, engajados numa variação contínua das variáveis ao invés de extrair delas constâncias, passamos a seguir um modelo ambulante, em um processo de desterritorialização que constitui e estende o território (científico). O que aparece de rivalidade entre as duas ciências (ibid, p. 41) é que nas ciências nômades, a ciência não está determinada a tomar um poder ou um desenvolvimento autônomo, já que todas as suas operações estão subordinadas às condições sensíveis ("seguir o fluxo de matéria, traçar e conectar o espaço liso"), enquanto nas ciências régias é próprio subtrair todas as operações de intuição e convertê-las em conceitos intrínsecos, categorias, teoremas e axiomas. Nelas, a desterritorialização implica reterritorialização no aparelho conceitual em que estão inscritas.

No campo da interação entre as ciências nômades e as ciências régias, os autores (ibid, p. 42) argumentam que

As ciências ambulantes contentam-se em inventar problemas, cuja solução remeteria a todo um conjunto de atividades coletivas e não científicas, mas cuja solução científica depende, ao contrário da ciência régia, e da maneira pela qual esta ciência de início transformou o problema, incluindo-o em seu aparelho teoremático e em sua organização de trabalho. (grifos dos autores)

Durante toda minha formação em química, rondava o ambiente o permanente sentimento de adequação ao que é ser um químico, o que é fazer química, a valoração desta profissão e a crítica a seus usos éticos, observando a história e a sociologia da ciência como norte, mas a química que se fazia em mim não era direita, não era correta, não estava cristalizando-se. A química que eu aprendia tinha uma função clara na ordem capitalista contemporânea, em sua função financeirizada, neoliberal e globalitária: buscava, como aponta Rolnik (2018), uma ampliação da minha força 
vital para se apropriar da minha potência de criação e da cooperação da qual tal potência depende para que se efetue em sua singularidade. Eu precisava estar sempre disponível, atento a qualquer possibilidade do novo, melhorar permanentemente quem eu era, colocar a disposição meus pensamentos... era o trabalho que não se valia do que eu poderia fazer, mas de quem eu era. A viadagem em mim ativou uma nova crise: a de que este capitalismo cognitivo (HARDT e NEGRI, 2016) não estava interessado neste corpo com desejos estranhos. Era necessário atuar para o apagamento do viado em mim, ou era necessário estabelecer resistências em um esforço de reapropriação coletiva da minha potência, para com ela construir o que Hard e Negri $(2014,2016)$ denominam de "o comum": eu precisava me tornar um viado-comum. Como operar em mim uma possibilidade de revolução micropolítica?

\section{Sobre as condições de emergência de uma educação química nômade}

Idealmente, deve-se permitir que a economia do desejo escape ao máximo à política de sobrecodificação do capitalismo, ao mesmo tempo suportando seu modo de funcionamento sem traumas. Não se trata de negar, de contornar os fluxos descodificados do capitalismo, mas dar-Ihes lugar próprio, e dentro do possível, governá-los. Segundo as conclusões de Guattari (1985), trata-se de criar condições que permitam aos indivíduos adquirir meios de expressão relativamente autônomos e relativamente não recuperáveis pelas tecnologias de formação do poder. A essas estratificações opõem-se micro-agenciamentos analítico-militantes suscetíveis de se cristalizar em torno de uma classe, uma escola, uma universidade:

Uma revolução, em qualquer domínio que seja, passa por uma libertação prévia de uma energia do desejo. E manifestadamente, só uma reação em cadeia, atravessando as estratificações existentes, poderá catalisar um processo irreversível de questionamento das formações de poder às quais está amarrada a sociedade atual (ibid, p. 67-68).

A individualização do desejo é a operação da produção de subjetividade capitalística, que instaura fenômenos de serialização, de identificação, que se presta à manipulação pelos equipamentos capitalísticos. Neste processo, a singularidade perde todo acúmulo processual possível. Deve-se, entretanto, estabelecer uma pragmática da produção de desejo, que, quando esmagadora, atinge não só o indivíduo, mas o grupo (Guattari $\&$ Rolnik, 2013).

Deleuze (2013) afirma que estamos transitando das sociedades disciplinares analisadas detalhadamente por Michel Foucault - para as sociedades de controle. Nelas, ações impostas continuamente, intensiva e ostensivamente, precocemente, 
passam a serem incorporadas pelos sujeitos das quais é objeto. Tornamo-nos não apenas dóceis, mas flexíveis. Tais sistemas de controle materializam sua existência na contenção e registro de informações acerca das ações de modo que possa, a qualquer momento, conferir, fiscalizar, examinar. (Veiga-Neto, 2008) Como nas sociedades de controle o homem nunca termina nada, encontramo-nos sempre endividados em relação ao tempo. Sibilia (2012) indica que nestes tempos pós, abunda a sensação de que o tempo é insuficiente e escoa rápido demais, tudo é urgente e tudo é veloz, tudo é instantâneo e mantemos constantemente a sensação de atraso. Tal sistema de controle interconectado, facilitado e barateado graças aos recursos da telemática, produz uma atitude dócil e resignada, atendendo disciplinarmente tudo o que exigem de nós, ainda que sejamos flexíveis e entramos estrategicamente no jogo (provoca nos sujeitos sobre o qual atua artimanhas e artifícios de escape, evasiva e - no limite da relação entre a própria subjetividade e as exigências do sistema - a recusa). (Veiga-Neto, 2008) Com base nesta nova configuração de mundo, a qual Guattari (1985) denomina capitalismo mundial integral e Toni e Negri $(2014,2016)$, império.

Rolnik (2016) argumenta que a relação entre as experiências de si e do mundo, simultâneas e indissociáveis, é paradoxal. No caso de uma micropolítica ativa, as duas capacidades de experiências encontram-se acionadas, conseguindo sustentar a subjetividade no mal-estar provocado pela tensão entre elas, cujo efeito é um devir de subjetividade e de seu campo relacional imediato capilarizando-se rizomaticamente pelo corpo do mundo. Em uma micropolítica reativa, o outro polo do espectro de micropolíticas - que nunca é puro - há uma desativação da potência do corpo em decifrar a experiência fora-do-sujeito, se constituindo como uma subjetividade cujo horizonte começa e termina no próprio sujeito. Neste caso, dispõe de duas opções para determinar a culpa por seu estado instável causado pelo paradoxo entre as experiências de si e do mundo: introjeta a causa de sua desestabilização, buscando meios para neutralizar a angústia, ou projeta numa suposta maldade de fora, elegendo um bode expiatório para o qual o corte de seu desejo será direcionado. (Rolnik, 2018) Já que a versão contemporânea do capitalismo intensifica o abuso perverso da força de trabalho, produz-se uma subjetividade flexível, gestora de sua potência funcional, aparentando favorecer uma liberdade de expansão vital. Todavia, reduz a subjetividade ao sujeito, desviando as potências de desejo de seu destino ético, na esperança de garantia de uma suposta estabilidade e sensação de pertencimento. Ao hierarquizar as relações e homogeneizar as práticas, são estabelecidos grupos sujeitados (Guattari, 2011) que tendem a ser manipulados por todas as determinações externas, e a ser dominado pela sua própria lei interna (o superego do grupo). A produção capitalística desse sujeito é sempre limite, tangencial, no sentido em que os afetos são radicalmente dissociados e suas desterritorializações são reduzidas ao estritamente necessário.

Frente ao motor do desejo que busca sempre lograr a vida, o que depende de negociar com as formas vigentes na superfície do mundo, de encontrar pontos onde o desejo poderá perfura-la para inscrever cortes de força instituinte, Suely Rolnik (2018) 
argumenta que para cumprir a sua função ética, o desejo em buscar estabelecer uma subjetividade que se coloca a altura do que acontece, a altura do inconsciente colonial-capitalístico, estabelece micropolíticas, individuais ou coletivas, que logram em recuperar sua potência.

A modelização dos sujeitos é contrária à lógica da multidão (Hardt \& Negri, 2014) em que as singularidades são negociadas em assembleias constituintes cujas temporalidades virais e autonomias políticas diferem dos rígidos movimentos de agenda globais, territorializados.

O mais importante são os modos de organização dos movimentos e, especificamente, os modos que incluem diferenças. As assembleias horizontais, democráticas, não esperam nem buscam unanimidade, mas sim são constituídas por um processo plural, que está aberto a conflitos e contradições. As decisões da maioria avançam através de um processo de inclusão diferencial, ou melhor, através da aglutinação de ideias. (Hardt \& Negri, 2014, p. 91)

A cooperação produtiva tende a ser criada em redes sociais entre produtores, sem necessidade de supervisão nem orientação burocráticas. Isto significa que, na percepção de Hardt e Negri (2014, p. 140), as rebeliões do início da década de 2010 marcam o surgimento do homem comum, uma pessoa comum que realiza uma tarefa extraordinária: abrir a propriedade privada ao acesso público; transformar a propriedade pública em comum; descobrir mecanismos para administrar, desenvolver mecanismos de sustentar a riqueza comum de maneira democrática, criando meios para a livre circulação de alimentos, de ideias, imagens, códigos e informações. Os autores afirmam que as condições para a emergência do homem comum são a capacidade de criar obrigações sociais comuns uns com os outros, o poder das singularizações para se comunicar por meio das diferenças, a segurança real dos destemidos e a capacidade da ação política democrática.

Ao avaliar as consequências da instalação das sociedades de controle no regime escolar (Deleuze, 2013), antecipa que nas instituições educacionais, as formas de controle tornam-se contínuas, em especial as avaliações; as ações de formação permanente agem pela escola e sobre ela; os programas de pesquisa das universidades são abandonados através da introdução da lógica de mercado em todos os níveis de ensino.

Hardt e Negri (2014) argumentam que a instituição educativa deve ser balizada por três princípios: tornar comuns os recursos, desenvolver planos de autogestão e sujeitar as decisões a procedimentos de participação democrática. Tomando por base a ideia de que conhecimento é o bem comum da educação e que o processo educativo não é meramente uma questão de obtenção de conhecimento, mas é desenvolvimento e exercício de nosso poder de pensar, defendem que o nível mais básico da educação é o autodidatismo produzido em instituições que propiciam relacionamentos (aí a não exclusão das figuras dos professores e das escolas) orientados para a condução de 
estudos. "A educação, por conseguinte, é sempre um exercício e uma demonstração em relação à igualdade de singularidades do comum" (Hardt \& Negri, 2014, p. 105), isto é, ao estudar, reconhece-se a inteligência dos outros e aprende-se beneficiando-se dela. As instituições de ensino, principalmente a de nível superior, tornaram-se cada vez mais empresariais e dirigidas pelo mercado já que perderam no último século grande parte do seu financiamento estatal - que as tornavam públicas e autônomas. Para estabelecerem-se como instituições do comum, os interesses da sociedade como um todo devem guiar os objetivos e pesquisas das universidades.

Nesse sentido, foi preciso que eu liberasse em mim micropolíticas ativas de reconhecimento do outro-em-mim, dos processos de ressonância entre meu desejo e as existências transviadas que foram atravessando minha história. Passei a conviver entre sapatões, travestis, mulheres e homens transgêneros, viadas afeminadas e militantes. O suor das saunas e o odor da ureia nos banheiros. As pálpebras dilatandose no escuro dos cinemas, e a dilatação muscular causada pelo volátil nitrito de amila. A compreensão dos efeitos tóxicos das siliconas, a hormonização traficada. As muitas maquiagens que exaltavam os olhares e que escondiam os hematomas. Era preciso que eu libertasse a química do seu lugar esterilizado para produzir novos conhecimentos, corporificados e localizados (Haraway, 1995). Qual objetividade a química se pretende, quando dela dependem as liberações dos corpos, quando dela deflagram as linhas de fuga suicidas?

\section{Sobre as possibilidades de um ensino de química transviado}

O pós-estruturalismo amplia a centralidade da linguagem, quando comparado ao estruturalismo de Saussure, já que a fixidez do significado se transforma em fluidez, indeterminação e incerteza. Foucault (2013) ultrapassa o entendimento de discurso como mera referência a coisas, não é um fenômeno de mera 'expressão' de algo. Para o autor, o discurso apresenta regularidades intrínsecas a si mesmo, através das quais é possível definir uma rede conceitual que é própria.

O significado, na concepção pós-estruturalista, deixa de ser pré-existente e passa a ser compreendido como produzido socialmente no interior de uma cultura. Mais do que sua fidelidade a um suposto referente, o importante será examinar as relações de poder envolvidas na sua área de produção. "Um determinado significado é o que é, não porque ele corresponde a um 'objeto' que exista fora do campo da significação, mas porque ele foi socialmente assim definido", afirma Silva (2004). A ênfase nos processos de significação é ampliada para uma desconfiança permanente das definições filosóficas de 'verdade' em que são baseados os saberes científicos e pedagógicos. A noção de verdade a partir de uma verificação empírica, de uma correspondência com a 'realidade', é abandonada para um questionamento sobre como se dá o processo em 
que algo é considerado verdade.

Em uma densa leitura pós-estruturalista do gênero, Judith Butler (2013) não identifica o gênero como uma identidade estável ou lócus da ação de vários atos, mas como uma identidade tenuamente constituída no tempo, instituído num espaço externo por meio de uma repetição estilizada de atos. A então aparência de substância do gênero, a naturalização do gênero como um pré-existente subjetivo, é uma realização performativa:

\begin{abstract}
Palavras, atos, gestos e desejo produzem o efeito de um núcleo ou substância interna, mas o produzem na superfície do corpo, por meio de um jogo de ausências significantes, que sugerem, mas nunca revelam, o princípio organizador da identidade como causa. [...] São performativos no sentido de que a essência ou identidade que por outro lado pretendem expressar são fabricações manufaturadas e sustentadas por signos corpóreos e outros meios discursivos. (ibid, p. 194.)
\end{abstract}

Dessa forma, estes enunciados performativos criam a ilusão de um núcleo interno e organizador do gênero. Tal ilusão deve ser mantida discursivamente unicamente com o propósito e regular a sexualidade nos termos da estrutura obrigatória da heterossexualidade reprodutora (ibid, p. 195). Estes atos performativos podem ser lidos como hábito (Hur, 2018) pela qual o sujeito tem realizada sua identidade. Tomado pela complexidade do contato com as multiplicidades propiciadas pelos fluxos de forças e movimentos em territórios, o ser reduz os dados contraindo-os em esquemas associativos, e, em sua mediação afetiva, articulam-se em novas configurações, compondo esquemas. Tais hábitos necessitam ser repetidos continuamente para a produção efetiva do ser e da subjetividade. A subjetividade resulta da composição de forças e articulações, estratos e fluxos, da acoplagem entre esquemas e materialidades, porta de um caráter paradoxal que de um lado estratifica e de outro desterritorializa, conjugando a estratificação ao movimento de devir. Quando pende para o lado molar, das micropolíticas reativas, uma subjetividade altamente codificada, opera pelo binarismo, dicotomias, pela lógica do negativo. Quanto menor o coeficiente de territorialização, maior autonomia nos processos de codificação, garantindo ao corpo o poder de ser afetado diminuindo, assim, as chances de captura pelos códigos. Surge a possibilidade de subjetivações moleculares.

É na possibilidade deste devir, de uma desidentificação com os modos de vida que o regime do inconsciente colonial-cafetinístico (Rolnik, 2018), que podemos pensar, com Paul B. Preciado (2018), a criação de uma nova aliança de movimentos críticos, inventando novas tecnologias de produção de vida e subjetividade, recusando posições estritamente especializadas: uma revolução transfeminista:

Nós somos o Parlamento pós-pornô que está por vir. Eles dizem "representar". Nós dizemos "experimentar". Eles dizem "identidade". Nós dizemos "multitude". Eles dizem "dívida". Nos dizemos "cooperação sexual e interdependência somática". Eles dizem "capital humano". Nós dizemos "aliança multiespécies". Eles dizem "crise". Nós dizemos "revolução". (ibid., p. 14) 
Preciado (2014) avalia a proposição butleriana de gênero enquanto performance e avalia que tal concepção ignora os processos materiais e corporais que as pessoas transgêneras e transexuais vivenciam na produção de seus corpos, assim como as técnicas de estabilização dos gêneros e do sexo que operam em função do corpo heterossexualizado:

O que as comunidades transexuais e transgênero colocaram em evidência não é tanto a performance teatral ou de palco dos gêneros (cross-gender), e sim as transformações físicas, sexuais, sociais e políticas dos corpos fora da cena; dito de outro modo, tecnologias precisas de transincorporação: clitóris que crescerão até se transforarem em órgãos sexuais externos, corpos que mudarão ao ritmo de doses hormonais, úteros que não procriarão, próstatas que não produzirão sêmen, vozes que mudarão de tom, barbas, bigodes e pelos que cobrirão rostos e peitos inesperados, dildos que terão orgasmos, vaginas reconstruídas que não desejarão ser penetradas por um pênis, próteses testiculares que ferverão a cem graus e poderão, inclusive, ser fundidas no micro-ondas... (ibid, p. 94).

Tendo em consideração que as cirurgias de redesignação sexual e o tratamento médico de crianças interssexo a partir da classificação sexual pela inspeção visual das genitálias de bebês, Preciado (2014) argumenta que arbitrariedade dos processos de identificação sexual e de gênero pode dar a lugar a estratégias maus fluídas, prostéticas, da experiência dos sujeitos no mundo.

El género (femineidad/masculinidad) no es ni un concepto, ni una ideología, ni una performance: se trata de una ecología política. La certeza de ser hombre o mujer es una ficción somatopolítica producida por un conjunto de tecnologías de domesticación del cuerpo, por un conjunto de técnicas farmacológicas y audiovisuales que fijan y delimitan nuestras potencialidades somáticas funcionando como filtros que producen distorsiones permanentes de la realidad que nos rodea. El género funciona como un programa operativo a través del cual se producen percepciones sensoriales que toman la forma de afectos, deseos, acciones, creencias, identidades. (Preciado, 2017).

Penso em como o vírus HIV, e os diversos "tratamentos" disponibilizados nas últimas décadas, faz do corpo-viado um molde de produção de novas estéticas. Nos efeitos colaterais do AZT e dos coquetéis, que resultavam na diminuição das reservas lipídicas do corpo, e em como a construção de corpos sarados em academias e os dispositivos da vida fitness remodelam sexos, desejos, estéticas. Lembro da alegria de amigas transgêneras quando mapeavam novos contornos de seus seios que brotavam às custas das altas doses de hormônios. Ainda me solidarizo com a aluna que, apesar do incômodo aparente ao responder à chamada como Paulo, vestia agasalhos no verão para esconder os seus seios siliconados durante as aulas, mas que fazia questão de os mostrar quando nos encontrávamos na boate, num sorriso largo, Paulette.

Ao denominar a sociedade de farmacopornopolítica, Preciado (2017) argumenta a 
partir da metade do século XX, o capitalismo especializou suas tecnologias biopolíticas para a criação de duas forças de produção de subjetividades sexuais: a introdução da noção de gênero como dispositivo técnico, visual e performativo de sexualização do corpo e a reorganização do sistema médico-jurídico, educativo e midiático para articular noções de normalidade em função díade homossexualidade/heterossexualidade. Um sistema baseado numa compreensão midiática dos processos bioquímicos em nossos corpos, instaurando forma de trabalho que não devem ser identificadas como imaterial, pela análise proposta por Hardt e Negri $(2014,2016)$, mas über-material, tendo que sua consistência é molecular e digitalizável, cujo objetivo último é a produção de ereções, de ejaculações, de volumes espermáticos (Preciado, 2017).

Este trabajo se caracteriza por la transformación em valor capital (plusvalía) del contacto de los cuerpos (virtual o actual), de la excitación de los centros bioquímicos de producción hormonal, de la producción y la transmisión de afectos, de la recepción de un impulso audiovisual, de la conexión del neocórtex con los vasos sanguíneos que irrigan el cuerpo cavernoso del pene, del clítoris, de la piel, de la reacción de los centros de producción de endorfinas y de oxitocina, de la respuesta em forma de placer inmediato o diferido de un metabolismo bioquímico preciso a una carta sustancia, etc. (Preciado, 2017, p. 197)

\section{Cuir-míca}

Eu não tô interessada no seu grande pau ereto Eu gosto mesmo é das bixas, das que são afeminada Das que mostram muita pele, rebolam, saem maquiada Eu vou falar mais devagar pra ver se consegue entender

Se tu quiser ficar comigo, boy (ha-ha-ha)

Vai ter que enviadescer

(Linn da quebrada)

Se a química se cristaliza sobre a égide de ser o pai da matéria e das suas transformações, pretendo pensar a química como a travesti-mãe que flerta ocasionalmente com a viadaafeminada na pista de dança. A possibilidade de construção molecular da química, uma aposta, dar-se-ia pelo estabelecimento de relações transversais que rompam com o binário sujeito-matéria. A criação de novos saberes em que a homossexualidade permitiria produção da dissolução da metafísica na qual a ciência tão devotamente se apoia.

$\mathrm{Na}$ análise da concepção de homossexualidade em Deleuze, Preciado (2014) identifica nos processos transversais exercidos por uma homossexualidade molecular a 
possibilidade de pensar ou escrever transversalmente sobre fenômenos sem passar pela experiência real, condição de possibilidade de certas experiências em "devir". É molecular porque dá o cu, afirma Preciado, num ato de criação que supõe uma "fecundação estéril" anal, assim como Deleuze concebia a história da filosofia como enrabadas: "Eu me imaginava chegando pelas costas de um autor e lhe fazendo um filho, que seria seu e, no entanto, seria monstruoso" (Deleuze, 2013).

O cu, estranhamente, é um lugar vazio de gênero (Saéz \& Carrascosa, 2011), já que o cu desafia a lógica do mito da cópula heterossexual. Todavia, a produção dos gêneros passa pela regulação do cu:

Esas líneas que lo controlan lo vigilan, lo estigmatizan, o lo promueven conforman una política. El culo es un espacio político. Es un lugar donde se articulan discursos, prácticas, vigilancias, miradas, exploraciones, prohibiciones, escarnios, odios, asesinatos, enfermedades. (ibid., 63)

Se a subjetividade heterossexual masculina se baseia numa abertura da boca, trazida para o espaço público, e um fechamento completo do cu, o primeiro órgão privatizado (Deleuze \& Guattari, 2011), a subjetividade heterossexual feminina exigirá uma privatização da boca e abertura pública do cu e da vagina, tecnicamente regulada por códigos morais (Saéz \& Carrascosa, 2011). Esta diferenciação do gênero heterossexual impõe ao sujeito homossexual uma existência vinculada ao sexo anal, atrelado a um discurso médico e psiquiátrico de patologia. Todavia, é possível causar um curtocircuito nas economias reprodutivas do sexo: enquanto no fistfuck o abandono do uso de genitais e a potencialização da mão como lugar inútil, nas comunidades sadomasoquistas as relações são negociadas e voluntárias, quem exerce o papel de "escravo" na realidade controla em grande parte a situação erótica.

A pesar de estas tradiciones condenatorias, existen em la actualidad comunidades y subculturas que han sabido apropiarse de lo anal para darle sentido positivo y orgulloso: las comunidades $\mathrm{S} / \mathrm{M}$, los practicantes del fist, el mercado porno, algunos/as filósofos/ as y activistas radicales, los aficionados al bareback, y ciertos sectores del feminismo radical pro-sexo y de las comunidades lesbianas queer (ibid, p. 172).

Quais as chances da produção de subjetividades transviadas, que escapem dos mecanismos de captura do inconsciente colonial-capitalístico? Das identidades e da lógica da exclusão de si e do outro, funções das micropolíticas reativas? O que tudo isso tem a ver com educação e química? Insistência. Insistência não pelo reforço do modelo, mas pela criação de novos espaços de viver, de uma educação que surja do $\mathrm{cu}$, que torne o cu público e a partir dele, possa produzir novos arranjos de existir baseados nas modalidades do homem-comum. Uma química que abandone a lógica binária e a arrogância do olhar sobre a matéria, para se refazer na matéria e a partir dela, produzir novos modos de existir. Que se apoie numa ética da multiplicidade que vá além do simples pluralismo, permitindo a abertura para processos que estão menos 
preocupados em validar e mais preocupados em viver. A insistência como um berro, que mistura gargalhadas e surpresa, mas que não quer deixar de ser ouvido.

\section{Referências bibliográficas}

Bachelard, G. (1996). A formação do espírito científico. Rio de Janeiro: Contraponto. Bachelard, G. (2009a). A pluralidade coerente da química moderna. Rio de Janeiro: Contraponto.

Bachelard, G. (2009b). A filosofia do não - Filosofia do novo espírito científico. $6^{\text {a }}$ ed. Lisboa: Editorial Presença.

Butler, J. (2013). Problemas de Gênero - Feminismo e Subversão da Identidade. $6^{\text {a }}$ ed. Rio de Janeiro: Civilização Brasileira.

Cardoso, L. R.; \& Paraíso, M. A. (2015). Dispositivo da experimentação e produção do sujeito homo experimentalis em um currículo de ciências. Educação em revista, 3(3), 299-320.

Cachapuz, A.; Gil-Perez, D.; Carvalho, A. M. P.; Praia, J.; \& Vilches, A. (2005). A necessária renovação do ensino das ciências. São Paulo: Cortez.

Deleuze, G. (2013). Conversações. $3^{\mathrm{a} e d}$. Rio de Janeiro: Editora 34.

Deleuze, G.; \& Guattari, F. (1997). Mil platôs - Capitalismo e esquizofrenia 2. Vol. 5. Rio de Janeiro: Editora 34.

Deleuze, G.; \& Guattari, F. (2011). O Anti-Édipo - Capitalismo e esquizofrenia 1. $2^{\mathrm{a}}$ ed. Rio de Janeiro: Editora 34.

Deleuze, G.; \& Guattari, F. (2012). Mil platôs - Capitalismo e esquizofrenia 2. Vol 4. $2^{\text {a }}$ ed. Rio de Janeiro: Editora 34.

Demeo, S. (2005). Gazing ate the hand: a foucaultian view of the teaching of manipulative skills to introductory chemistry students in the United States and the potential for transforming laboratory instrution. Curriculum Inquiry, 35(3), 295-338.

Fischer, R. M. B. (2012). Trabalhar com Foucault. Belo Horizonte: Autêntica. 
Foucault, M. (1979). Microfísica do Poder. Rio de Janeiro: Graal.

Foucault, M. (2013). A arqueologia do Saber. $8^{a}$ ed. Rio de Janeiro: Forense Universitária.

Foucault, M. (2014). Ditos e Escritos, volume IX: Genealogia da ética, subjetividade e sexualidade. Rio de Janeiro: Forense Universitária.

Gough, N. (2007). Geophilosophy, rhizomes and mosquitoes: becoming nomadic in global, science education research. In: B. Atweh; M. Borba; Barton, A. C.; D. Clark; N. Gough; C. Keitel; C. Vistro-Yu; \& R. Vithal (orgs.) Internationalisation and globalisation in mathematics and science education. Dordrecht: Springer.

Guattari, F. (1985). Revolução Molecular - pulsações políticas do desejo. $2^{\mathrm{a}}$ ed. São Paulo: Brasiliense.

Guattari, F. (2011). Da Produção de Subjetividade. In A. Parente (orgs) Imagemmáquina. $4^{\mathrm{a}} \mathrm{ed}$. Rio de Janeiro: Editora 34.

Guattari, F.; \& Rolnik, S. (2013). Micropolítica - Cartografias do desejo. $12^{\mathrm{a}} \mathrm{ed}$. Petrópolis: Vozes.

Haraway, D. (1995). Saberes localizados: a questão da ciência para o feminismo e o privilégio da perspectiva parcial. Cadernos Pagu, 5(1), 7-41.

Hardt, M.; \& Negri, A. (2014). Declaração - Isto não é um manifesto. São Paulo: n-1 edições.

Hardt, M.; \& Negri, A. (2016). Bem estar comum. Rio de Janeiro: Record.

Lôbo, S. F. (2007). O ensino de química e a formação do educador químico, sob o olhar bachelardiano. Ciência \& Educação, 14(1), 89-100.

Lôbo, S. F. (2012). O trabalho experimental no ensino de química. Quím. Nova, 35(2), 430-434.

Ó, J. R. (2013). Foucault e o problema da escrita: uma introdução. In S. M. Clareto; \& A. Ferrari (orgs) Foucault, Deleuze \& Educação. Juiz de Fora: Editora UFJF.

Preciado, P. B. (2014). Manifesto contrassexual - Práticas subversivas de identidade sexual. São Paulo: $n-1$ edições.

Preciado, P. B. (2017). Testo Yonqui. $4^{\text {a }}$ ed. Barcelona: Espassa Líbro.

Preciado, P. B. (2018) 
Preciado. P. B. (2018). Transfeminismo. In Pandemia (org.) Cordéis. São Paulo: n-1 edições.

Ramos, F. P.; Danhoni, M. C.; \& Corazza, M. J. (2011). A ciência moderna e as concepções contemporâneas em discursos de professores-pesquisadores: entre rupturas e a continuidade. Revista Eletrónica de Enseñanza de las Ciências, 10(1), 84108.

Rezende, F. S.; Ferreira, L. N. A.; \& Queiroz, S. L. (2010). Concepções a respeito da construção do conhecimento científico: uma análise a partir de textos produzidos por estudantes de um curso superior de química. Revista Eletrónica de Enseñanza de las Ciências, 9(3), 596-617.

Richardson, L. (2001). Getting Personal: Writing-stories. International Journal of Qualitative Studies in Education, 14(1), 33-38.

Rolnik, S. (2018). Esferas da insurreição - Notas para uma vida não cafetinada. São Paulo: $\mathrm{n}$-1 edições.

Rolnik, S. (2016). A hora da micropolítica. In Pandemia (org.) Cordéis. São Paulo: n-1 edições.

Saéz, J.; \& Carrascosa, S. (2011). Por el culo - Políticas Anales. Barcelona: Editorial Egales.

Sibila, P. (2012). Redes ou paredes - A escola em tempos de dispersão. Rio de Janeiro: Contraponto.

Silva, T. T. (2004). Documentos de identidade - Uma introdução às teorias de currículo. $2^{\mathrm{a}}$ ed. Belo Horizonte: Autêntica.

Veiga-Neto, A. (2008). Crise da modernidade e inovações curriculares: da disciplina para o controle. Sísifo/Revista de Ciências da Educação, XXIII(79), 163-186.

Allan Moreira Xavier é professor adjunto do Centro de Ciências Naturais e Humanas da Universidade Federal do ABC. Licenciado e bacharel em Química pela Universidade Estadual de Campinas, mestre em nanociências e materiais avançados e doutor em Ciência e Tecnologia, com tese defendida na área de educação química, ambos pela Universidade Federal do ABC. Atualmente, coordena o Laboratório de Investigações na

Diferença: Educação e Sexualidades. 